\title{
Effect of leaf juice of Catharanthus roseus Linn on cholesterol, triglyceride and lipoproteins levels in normal rats
}

Catharanthus roseus Linn (Apocyanaceae) is a herbaceous subshrub also known as Madagascar periwinkle, Vinca rosea, or Lachnera rosea worldwide. The leaves are used traditionally in various regions of the world including India, West Indies as well as Nigeria to control diabetes. ${ }^{[1]}$ The leaves have been known to contain 150 useful alkaloids among other pharmacologically active compounds. Significant antihyperglycemic and hypotensive activity of the leaf extracts (hydroalcoholic or dichloromethane-methanol) have been reported in laboratory animals. ${ }^{[2]}$ Fresh leaf juice of $C$. roseus has been reported to reduce blood glucose in normal and alloxan diabetic rabbits. ${ }^{|3|}$ The present study was aimed at evaluating the effect of the leaf juice on cholesterol, triglyceride and proteins levels in rats.

Fresh leaves of $C$. roseus (red variety) were collected in July, 2003, from the Faculty of Pharmacy farm, University of Uyo, Uyo, Nigeria and authenticated by Dr. (Mrs.) Margaret Bassey, a taxonomist in Department of Botany, University of Uyo, Uyo. The leaves $(2 \mathrm{~kg})$ were crushed in a laboratory wooden mortar and squeezed by means of a fine cloth to separate the juice $(13.6 \mathrm{ml})$. The juice was stored in a refrigerator at $4^{\circ} \mathrm{C}$ until used for the experiment.

Adult albino Wistar rats (180-220 g) of either sex were obtained from University of Uyo animal house. The animals were acclimatized for 10 days at room temperature $\left(30 \pm 5^{\circ} \mathrm{C}\right)$ and $50 \%$ humidity. They were maintained on standard animal pellets and water ad libitum. Permission and approval for animal studies were obtained from the College of Health Sciences animal ethics committee, University of Uyo.

The rats were randomly assigned on the basis of weight into four groups of five animals each. Groups A-C received orally, the fresh leaf juice of $C$. roseus at $0.1,0.5$ and $1.0 \mathrm{ml} /$ $\mathrm{kg} /$ day, respectively, for seven consecutive days. The doses were determined based on a previous work on the plant. ${ }^{|3|}$ The control group (Group D) received $3 \mathrm{ml} / \mathrm{kg}$ of normal saline orally. Twenty-four hours after the last dose, the animals were anesthetized with diethyl ether and blood collected through cardiac puncture into sample bottles devoid of anticoagulant. The samples were centrifuged at $1000 \mathrm{rpm}$ for $10 \mathrm{~min}$ to obtain the sera. Serum total cholesterol, triglyceride and highdensity lipoprotein (HDL) levels were measured by enzymatic colorimetric methods using Quinica Clinica Aplicada, S.A. reagent kits. All samples were analysed with a WinelightUnicam spectrophotometer. The concentration of low-density lipoprotein (LDL) and very low-density lipoprotein (VLDL) was calculated by the formula of Friedewald. ${ }^{[4]}$

Data are expressed as mean \pm SEM. All data were statistically analysed using the one-way ANOVA followed by Tukey-Kramer post-test and $\mathrm{P}<0.05$ was considered significant.

The leaf juice of $C$. roseus produced a significant decrease in serum total cholesterol, total triglyceride, LDL-cholesterol and VLDL-cholesterol of rats. [Table 1] The decreases were only significant $(P<0.05)$ at the highest dose of the juice $(1.0 \mathrm{ml} / \mathrm{kg})$ compared to control in the case of total cholesterol, triglyceride, LDL-cholesterol and VLDL-cholesterol. However, the level of HDL cholesterol was not altered by any of the doses studied.

In the present study, there was a significant reduction in the levels of total cholesterol, triglycerides, LDL and VLDL

Table 1

Effect of Catharanthus roseus Leaf Juice on serum lipoprotein levels in rats

\begin{tabular}{|c|c|c|c|c|c|c|}
\hline \multirow[t]{2}{*}{ Group } & \multirow[t]{2}{*}{$\begin{array}{c}\text { Dose } \\
\mathrm{mg} / \mathrm{kg}(\text { p.o.) }\end{array}$} & $\begin{array}{c}\text { Total } \\
\text { cholesterol }\end{array}$ & Triglyceride & $\begin{array}{c}H D L \\
\text { cholesterol }\end{array}$ & $\begin{array}{c}L D L \\
\text { cholesterol }\end{array}$ & $\begin{array}{c}V L D L \\
\text { cholesterol }\end{array}$ \\
\hline & & \multicolumn{5}{|c|}{ (Mmol/I) } \\
\hline Saline (control) & - & $3.57 \pm 0.13$ & $2.64 \pm 0.07$ & $0.74 \pm 0.07$ & $3.35 \pm 0.12$ & $0.53 \pm 0.02$ \\
\hline Leaf juice & 0.1 & $3.33 \pm 0.18$ & $2.53 \pm 0.08$ & $0.70 \pm 0.05$ & $3.02 \pm 0.16$ & $0.51 \pm 0.03$ \\
\hline Leaf juice & 0.5 & $3.28 \pm 0.05$ & $2.45 \pm 0.16$ & $0.77 \pm 0.05$ & $3.00 \pm 0.03^{*}$ & $0.49 \pm 0.07$ \\
\hline Leaf juice & 1.0 & $3.05 \pm 0.16^{*}$ & $2.06 \pm 0.05^{*}$ & $0.81 \pm 0.08$ & $2.78 \pm 0.13^{*}$ & $0.41 \pm 0.02^{*}$ \\
\hline One-way & $F$ & 5.0 & 10.66 & 0.33 & 6.75 & 0.33 \\
\hline ANOVA & $\mathrm{P}$ & $<0.05$ & $<0.05$ & $>0.05$ & $<0.05$ & $>0.05$ \\
\hline
\end{tabular}

Values are mean \pm SEM. $n=5$ in each group. ${ }^{*} P<0.05$ compared to control; $d f=3,16$. 
cholesterol. This reduction in the levels of the LDL and VLDL could have resulted from the antioxidant effect of the fresh leaf juice of $C$. roseus, whose phytochemical components include flavonoid, which is known for antioxidant effect. ${ }^{[5]}$ Further investigations are warranted to identify the hypolipidemic active principles and elucidate their mechanism of action.

B.S. ANTIA, *J.E. OKOKON

Department. of Chemistry, University of Uyo, Uyo - Nigeria *Department of Pharmacology and Toxicology, Faculty of Pharmacy, University of Uyo, Uyo - Nigeria E-mail: judeefiom@yahoo.com

\section{References}

1. Cowley RC, Bennett FC. Vinca rosea. Australian J Pharm 1928;9:61.

2. Pillay PP, Nair CPM, Santi Kumari TN. Lochnera rosea as a potential source of hypotensive and other remedies. Bull Research Inst Univ Kerala ser A6. 1959;1:51-4.

3. Nammi S, Boini, MK, Lodagala S, Behara RBS. The juice of fresh leaves of Catharanthus roseus Linn. Reduces blood glucose in normal and alloxan diabetic rabbits. BMC complementary and Alternative Medicine 2003;2:3-4.

4. Friedewald WI, Levy RI, Fredrickson DS. Estimation of the concentration of low density lipoprotein cholesterol in plasma, without use of the preparative ultracentrifuge. Clin Chem 1972;18:499-502.

5. Afanas'ev IB, Ostrachovitch EA, Abramova NE, Korkina LG. Different antioxidant activities of biflavonoid rutin in normal and iron overloading rats. Biochem Pharmacol 1995;80:627-35.

\section{A VERY BRIEF INTRODUCTION TO OPEN ACCESS}

Open-access (OA) literature is digital, online, free of charge, and free of most copyright and licensing restrictions. What makes it possible is the Internet and the consent of the author or copyright-holder.

In most fields, scholarly journals do not pay authors, who can therefore consent to OA without losing revenue. In this respect scholars and scientists are very differently situated from most musicians and movie-makers, and controversies about OA to music and movies do not carry over to research literature.

$O A$ is entirely compatible with peer review, and all the major $O A$ initiatives for scientific and scholarly literature insist on its importance. Just as authors of journal articles donate their labor, so do most journal editors and referees participating in peer review.

OA literature is not free to produce, even if it is less expensive to produce than conventionally published literature. The question is not whether scholarly literature can be made costless, but whether there are better ways to pay the bills than by charging readers and creating access barriers. Business models for paying the bills depend on how OA is delivered. There are two primary vehicles for delivering OA to research articles: OA journals and OA archives or repositories.

* OA archives or repositories do not perform peer review, but simply make their contents freely available to the world. They may contain unrefereed preprints, refereed postprints, or both. Archives may belong to institutions, such as universities and laboratories, or disciplines, such as physics and economics. Authors may archive their preprints without anyone else's permission, and a majority of journals already permit authors to archive their postprints. When archives comply with the metadata harvesting protocol of the Open Archives Initiative, then they are interoperable and users can find their contents without knowing which archives exist, where they are located, or what they contain. There is now open-source software for building and maintaining OAl-compliant archives and worldwide momentum for using it. The costs of an archive are negligible: some server space and a fraction of the time of a technician.

* OA journals perform peer review and then make the approved contents freely available to the world. Their expenses consist of peer review, manuscript preparation, and server space. OA journals pay their bills very much the way broadcast television and radio stations do: those with an interest in disseminating the content pay the production costs upfront so that access can be free of charge for everyone with the right equipment. Sometimes this means that journals have a subsidy from the hosting university or professional society. Sometimes it means that journals charge a processing fee on accepted articles, to be paid by the author or the author's sponsor (employer, funding agency). OA journals that charge processing fees usually waive them in cases of economic hardship. OA journals with institutional subsidies tend to charge no processing fees. OA journals can get by on lower subsidies or fees if they have income from other publications, advertising, priced add-ons, or auxiliary services. Some institutions and consortia arrange fee discounts. Some OA publishers waive the fee for all researchers affiliated with institutions that have purchased an annual membership. There's a lot of room for creativity in finding ways to pay the costs of a peer-reviewed OA journal, and we're far from having exhausted our cleverness and imagination.

For a longer introduction, with live links for further reading, see my Open Access Overview:

http://www.earlham.edu/ peters/fos/overview.htm.

PETER SUBER

Open Access Project Director, Public Knowledge, Research Professor of Philosophy, Earlham College, Senior Researcher, SPARC. E-mail: peters@earlham.edu

Copyright (C) 2004-2005, Peter Suber. This is an open-access document 